\title{
Tom Isaacs: Co-Founder and President, The Cure Parkinson's Trust
}

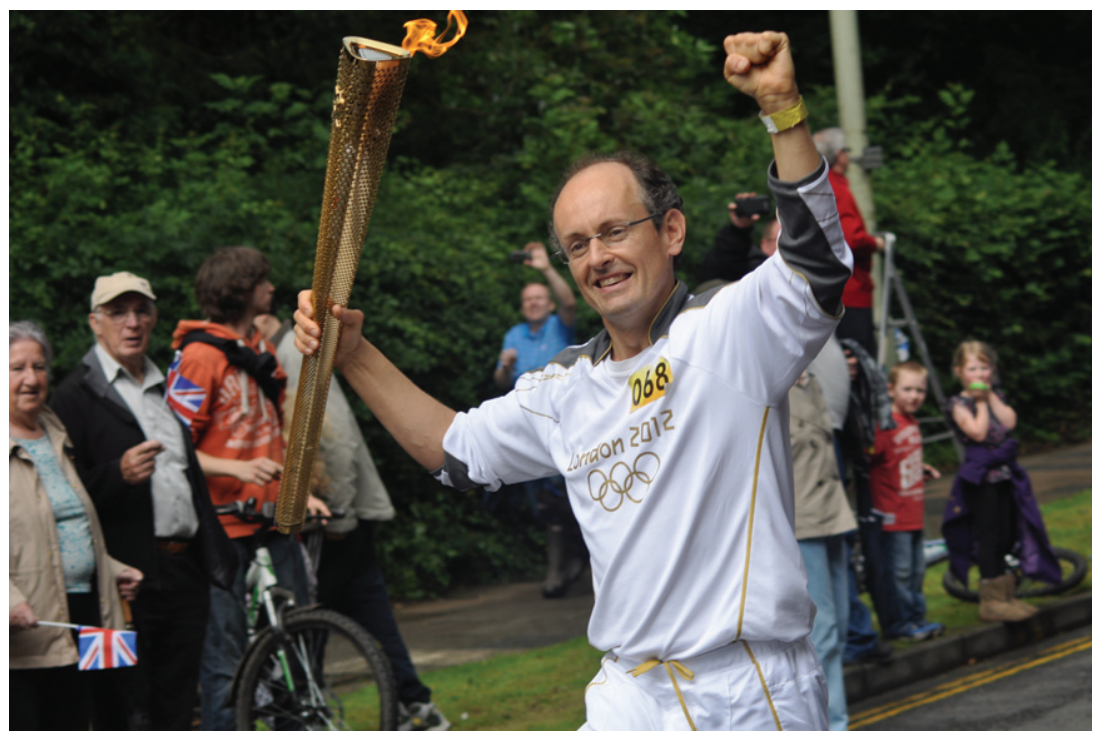

Tom Isaacs was diagnosed with Parkinson's at the young age of 26 and worked tirelessly to challenge the view that Parkinson's was incurable, raising funds for research to trial new treatments and becoming one of the most well-known and popular international patient advocates.

Having completed a successful 1,250 mile sponsored walk in 1999, Tom was determined to use his Parkinson's to achieve more in life than he could have done without it, leaving his job as Director of a London property company to undertake his Coastin' challenge to raise funds for Parkinson's research. He walked 4,500 miles around the British coastline, climbed the highest mountains in England, Scotland and Wales and ran the Flora London Marathon, raising over $£ 350,000$ for Parkinson's research. He wrote a book, Shake Well Before Use about his walk and his experiences living with Parkinson's which he conveys with passion, optimism and humour.

In 2004 he was awarded UK Charity Personality of the Year and a year later he helped to co-found The Cure Parkinson's Trust (CPT), a patient-led charitable organisation of which he was President. The name alone challenged the view that Parkinson's was incurable. "I still maintain that one day I will be able to insert the word 'used to' when I say I have Parkinson's." Tom said. Over ten years on and under Tom's guidance, CPT is recognised as a key player in the world of research and has funded over \$7.4 million of Parkinson's research projects.

In the early days of CPT, Tom and the charity's Director of Research and Development Dr Richard Wyse, forged ahead with international collaborations. The first was with Patrik Brundin (of the Van 
Andel Institute in Grand Rapids, Michigan) who they approached about developing a research programme to re-purpose existing drugs and investigate their potential to slow, stop or reverse Parkinson's. Dr Brundin described Tom as "a beacon of light who guided us all doing Parkinson's research, keeping us on track." This project became the Linked Clinical Trials (LCT) initiative, now driven by a 14-strong international Committee of neurologists and Parkinson's researchers. LCT is in its fifth year and to date there are eight drugs within the trial programme.

Once described as "the most expert patient" Tom was able to take part in scientific discussions at the highest level and his passion, charm and singlemindedness helped him earn the respect and support of such leading Parkinson's researchers as Dr Patrik Brundin and Professors Andrew Lees, Anders Bjorkland, Roger Barker and Steven Gill.

Tom worked closely and successfully with many international organisations including the Van Andel Research Institute and the Michael J Fox Foundation. He was also a Board Member of the European Parkinson's Disease Association from 2005 until 2010.

Tom was the first person with Parkinson's to speak at the World Parkinson Congress in 2006. He has attended and presented at every WPC since and was also the patient representative on the Steering Committee and chaired the Patient Advocacy Committee for the World Parkinson Congress in 2010 and 2013. "He was a leader from the day of his diagnosis and he dreamed about helping others with PD to also become leaders to march alongside him in his journey to end Parkinson's disease." says Eli Pollard, Executive Director of the World Parkinson Coalition. At the 2016 World Parkinson Congress, Tom was awarded the inaugural prize for Distinguished Contribution to the Parkinson's Community.

He was also a leading contributor to the SENSEPARK project in 2011, a European funded initiative which established more personalised, objective measuring devices for people with Parkinson's and those who treat them. He co-founded Parkinson's Movement, which provided a voice for people with Parkinson's and has made progress in addressing some of the problems experienced in clinical trials - in particular, recruitment and outcome measures.

In 2012 Tom was awarded the prestigious, Dr Rana International Parkinson's Community Service Award and was also one of the torchbearers in the run up to the 2012 Olympic Games.

Tom has written articles and been published in the Lancet Neurology, the Journal of Clinical Investigations and the Journal of Parkinson's Disease for which he was on the editorial board.

He was married to Lyndsey, an acupuncturist and former nurse who fully embraced Tom's vision and was an advocate for Parkinson's in her own right. Her phenomenal support for Tom enabled them to travel extensively to attend conferences and meetings at which Tom gave speeches and presentations about the urgent need for a cure, the power of advocacy in research and the impact of living with Parkinson's. Tom and Lyndsey not only shared a vision but also a wonderful sense of humour, friendship and fun.

Perhaps most important of all, Tom inspired people with Parkinson's, giving hope that a cure will be found and a belief that the patient voice was being heard. He spoke openly about his condition and helped fellow patients understand they were not alone, describing hope as 'the best medicine of all.' As one CPT supporter said, "The PD world has lost a hero and a trailblazer."

Tom Isaacs, co-founder and President of The Cure Parkinson's Trust was born on April 21968 and died on May 31st, 2017, aged 49. www.cureparkinsons.org.uk 